\title{
HYBRID LASER WELDING: A REVIEW
}

\author{
CASAlino, G.; DAL MASO, U.; \\ Angelastro, A. \& CAMPANELli, S.L.
}

Abstract: Nowadays, hybrid welding technology can be defined as the combination of a laser heat source with a secondary welding source, typically an electric arc. The hybrid welding processes have some advantages over arc welding and laser welding like high welding speeds, reduction of edge preparation accuracy, control of metallurgical variables through the addition of filler wire and higher electrical efficiency. Nevertheless a large number of process parameters needs to be checked to obtain these good results. Moreover the numerous process parameters governing the hybrid weld process are modified with the change of coupling of welding sources and with new materials to be welded. In this work an overview of the state of the art about process development, experimental analysis and related industrial applications of hybrid laser welding is given. This paper explains the basics of the process and traces the most relevant worldwide research. The authors wish to stimulate the onset of further research on hybrid laser welding.

Key words: hybrid laser welding, review
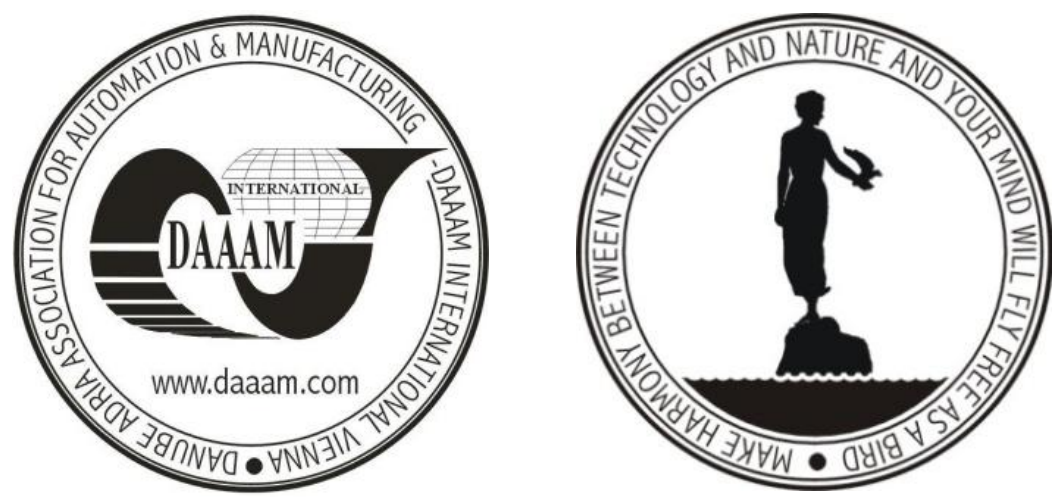

Authors' data: Prof. Ing.Casalino, G[iuseppe]; Ing. Dal Maso, U[mberto]; Ing. Angelastro, A[ndrea]; Ing. Campanelli, S[abina] L[uisa]; DIMeG Politechnic of Bari, Viale Japigia 182, 70126, Bari, Italia, g.casalino@poliba.it, u.dalmaso@poliba.it, a.angelastro@poliba.it, campanel@poliba.it

This Publication has to be referred as: Casalino, G[iuseppe]; Dal Maso, U[mberto]; Angelastro, A[ndrea] \& Campanelli, S[abina] L[uisa] (2010). Hybrid laser welding: A review, Chapter 38 in DAAAM International Scientific Book 2010, pp. 413-430, B. Katalinic (Ed.), Published by DAAAM International, ISBN 978-3-901509-74-2, ISSN 1726-9687, Vienna, Austria

DOI: $10.2507 /$ daaam.scibook.2010.38 
Casalino, G.; Dal Maso, U.; Angelastro, A. \& Campanelli, S.L.: Hybrid Laser Wel...

\section{Introduction}

Hybrid laser welding is based on coupling to a laser source a technologically different heat source. The basic idea is to maximize the advantages and reduce the drawbacks characterizing the individual welding processes. In the late seventies W. M. Steen (Steen, 1980) presented the first hybrid welding process combining a laser with a tungsten inert gas (TIG) source. In subsequent years the technology of high power laser sources grew up and so laser welding became a profitable and reliable process for industry (Ready, 1997). The widespread use of the laser welding process in industry over the years has also highlighted its disadvantages (cost, edge preparation and positioning, metallurgical problems). It was found that its drawbacks could be minimized or suppressed by using a laser coupled with a conventional arc welding method. In fact, the conventional arc welding methods increased the efficiency of the process, minimized metallurgical difficulties and reducing the difficulties related to the reflectivity of the material (Seyffarth\& Krivtsun, 2002; Steen, 2003). So the evolution of laser welding and hybrid welding in industry has been strictly related to the development of high power laser equipment. The savings resulting from the use of a hybrid welding process in the years represented the reason of investigations about hybrid laser-arc welding in several scientific and industrial environments (Magee et al., 1990; Beyer et al., 1994;Dilthey \& Wieschemann, 1999; Ishide et al., 2002). The tailored blank industry was the first on investing on the hybrid laser-arc welding because of the need of wide high quality welds made at high speed; afterwards many industrial fields were attracted by the process such as the construction, ship building and the pipeline industries. Today joining of metallic materials by the application of hybrid laser-arc welding techniques has been brought to several industrial applications until the design of integrated hybrid welding heads (Bagger \& Olsen, 2005). In addition a high automation welding process could be achieved using robot for three-dimensional welding tasks. Nevertheless, a lot of different demands and related questions need to be tested and modelled. The material to be joined can be of particular importance in a hybrid laser-arc welding process. The geometry (thickness and joint shape) of the workpieces needs to be systematically investigated.

\subsection{Hybrid laser-arc welding process development}

Laser welding has many advantages such as high welding speed, and so high productivity, and a low heat input resulting from the high concentration of energy. Reduced post weld rework, absence of mechanical contact between the laser equipment and the workpieces, wide possibility of join dissimilar materials are many important advantages. These advantages reveal some drawbacks of the process, because of the requirement of an accurate machining and positioning of the pieces to be welded. Further disadvantages are high cost of equipment and maintenance, limited welding positions, poor electrical efficiency, and sometimes (e.g. duplex stainless steel) metallurgical problems due to the high cooling rates. Moreover materials with high reflectivity often result difficult to weld and metallurgical problems are consequently frequent. So laser welding could be very expensive for 
several applications. In order to avoid these problems a hybrid welding technique has been developed, which combines the laser welding process with an arc process, namely hybrid laser-arc welding. In hybrid laser-arc welding a laser $\left(\mathrm{CO}_{2}\right.$ or $\left.\mathrm{YAG}\right)$ is combined to an arc process (TIG, MIG, MAG or plasma). The laser beam offers the possibility of producing deeper welds in one pass, whereas the arc energy is used to increase welding speed and to fill the fit-up defects between the pieces to be joined. To sum-up, hybrid laser-arc welding combines the advantages of both arc and laser processes with increased tolerance to fit up and without compromising joint quality and distortion control. The benefits to industry include increased productivity, simplified set-up procedures and reduced post weld reworking costs. However, this technology is experiencing only slow growth in today's industries. Some reasons for this slow acceptance are the high cost of the investment and the complexity of the process due to its large number of parameters. The set up of the processing parameters requires a high degree of skill and accuracy, and these imperatives, added to an incomplete knowledge of the process, are limiting factors for the industrial application. Most of today's applications for hybrid welding are limited to sheet materials in the range of 1 to $10 \mathrm{~mm}$, but thick materials may also derive benefits from this joining process. In recent years, with the industrial development of shipbuilding and car manufacturing, where deep weld penetration and welding of thick steel plates and Aluminium alloys may be needed, investigations of laserMIGIMAG hybrid welding have became more attractive and have already been carried out for practical application in many industrial fields (Graf\&Staufer, 2003; Jasnau et al., 2004). The importance of investigating the actual influence of the main process parameters and the repeatability of the overall application, are thus crucial goals to be achieved.

\section{Hybrid laser-arc welding process description}

Although the hybrid laser-arc welding offers significant advantages compared to laser welding and arc welding, the coupling of the two processes leads to an increase in the number of parameters. Moreover each value of parameter, which is right for the single process, is probably not optimal for a successful welding with a hybrid process since parameters heavily influence each other. So an accurate study of all these parameters is fundamental for the process stability and repeatability, maximize penetration, dimensional and mechanical characteristics of joints and cost to power ratio optimization. The type of laser source used, typically $\mathrm{CO}_{2}$ or $\mathrm{Nd}$ : YAG, and so related wavelengths, is an important parameter that needs to be considered becauseaffects the choices of the other process parameters. Nd: YAG laser radiation, due to a lower interaction with the arc's plasma, allows a closer approach to the arc than $\mathrm{CO}_{2}$ laser radiation, so the distance between the sources it's dependent on the type of laser source (Petring et al., 2003). In laser welding an increase of laser power induces a growing of penetration. In hybrid laser welding this phenomenon is often emphasized because the reflectivity of the workpiece metal is reduced when the metal is heated by the arc. In recent years the fibre lasers, characterized by a continuous increasing output power and a high beam quality, capture application fields which are 
difficult for the high power $\mathrm{CO}_{2}$ lasers, such as titanium alloys welding ( $\mathrm{Li}$ et al., 2009). The hybrid laser-arc process could be realized using two different layouts for heat sources, or rather laser source could be the first that welds the metal (Laser leading hybrid process) or the last one (Arc leading hybrid process). The choice depends on several factors, such as metal base characteristics, power of laser source, type of arc source.

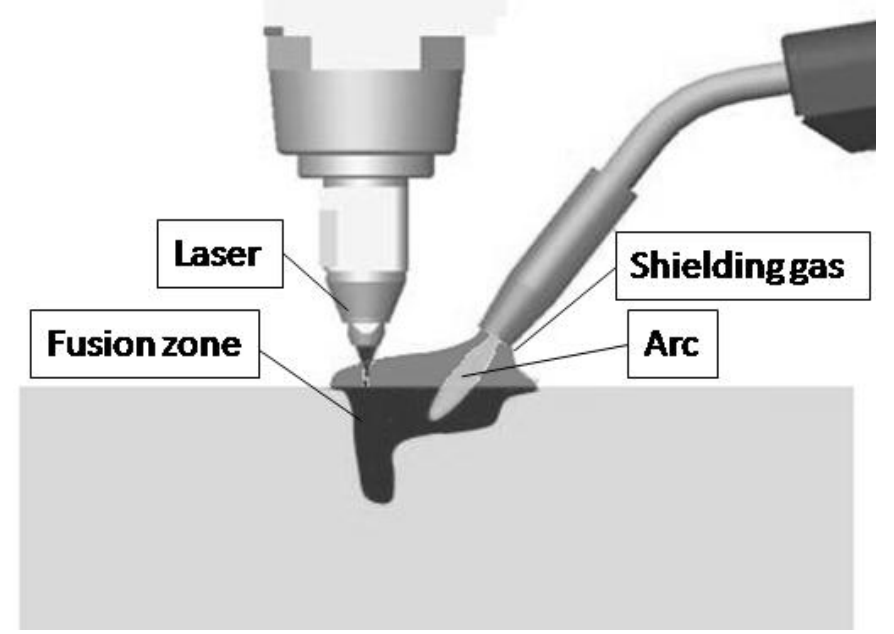

Fig. 1. Hybrid laser arc welding process

Moreover, the distance between the laser source and the arc is an important parameter to control the penetration in hybrid laser-arc welding and normally consists of a value of few millimetres.Shielding gas parameters, such as the composition and the protecting method, have a key role in the hybrid laser-arc process. The weld penetration and the arc stability depend on the shielding gas too. The weld penetration of hybrid welding was determined by the plasma shape which varies with the shielding gas parameters (Gao et al., 2007). In high power $\mathrm{CO}_{2}$ laser welding, the laser induced plasma resulting from the ionization of the shielding gas at the laser incident point could dissipate the laser energy, decreasing the weld penetration and even bringing on the disappearance of laser keyhole (Beck et al., 1995). The shielding gas is generally composed by a high rate of an inert gas such as helium or argon. When $\mathrm{CO}_{2}$ lasers are employed, the process needs a higher ionization potential shielding gas because the plasma can deflect or absorb a portion of the laser energy. Helium, with a high ionization potential, is so preferred to emphasize penetration effects; on the other hand Argon enhances the arc stability. Moreover a reactive gas such as oxygen and carbon dioxide has an influence on the weld pool wetting characteristics and bead smoothness. The protection method involves the number, the diameter, the flow and the arrangement of gas nozzles with respect to the heat sources, such as paraxial (leading or trailing) or coaxial.Gas metal arc stability is emphasized when it combines with a laser beam (Diltheyet al., 1999). In order to achieve this enhancement, the arc must be close enough to the laser beam so they share the same fusion pool.In fact if the sources are too distant the synergetic effects of hybrid techniques are lost, the arc becomes instable and the penetration decreases.Nevertheless if the distance is too short the laser beam is absorbed by the 
laser and arc plasmas and the metal filler drops blocks the penetration of laser beam (Ishideet al., 2003).

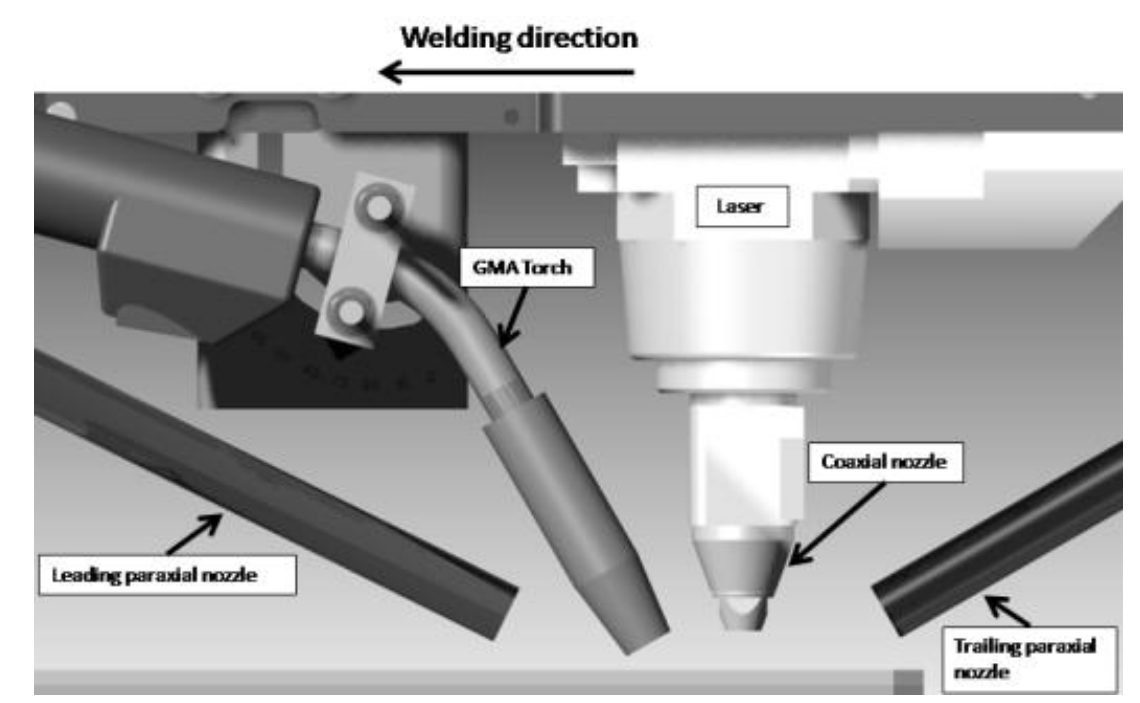

Fig. 2. Shielding gas

The distance influences the mixing phenomena between the deep and narrow molten pool deriving from laser source and the wide and superficial molten pool deriving from arc source. The optimal distance depends on many other factors, such as laser power, torch angle, arc size (arc parameters like current, voltage and pulsing). Kutsuna\& Chen, (Kutsuna\& Chen, 2002) studied thedistance that optimise the process efficiency. They found that it was equal to $2 \mathrm{~mm}$ for a hybrid process with a $2 \mathrm{~kW}$ laser powerand 200A arc current. This result shows the complexity of the process and so the absence of absolutely general rules. The laser beam focal position with respect to the surface of the piece and the welding current, affects the penetration of the weld. At constant laser power and welding speed, the higher the arc current, the deeper must be the focal point below the surface of the workpiece to achieve good penetration (El Rayes et al., 2004).In fact, if the arc current rises, grows up the depth of the weld pool. If the plane of focus the laser is placed on the workpiece surface, it doesn't act inside the resulting weld pool and so the maximum penetration can't be reached. To sum up, the maximum weld penetration for the hybrid laser-arc process is generally obtained when the laser beam is focused below the top sheet surface, with a value related to welding current. The base metal transfer mode is important in order to achieve a stable and repeatable process: pulsed/sprayarc should be preferred to short/globular-arc, which induces a lower turbulence caused by the small filler metal drops impacting the weld pool (Campana et al., 2007).The angle of electrode affects the penetration of the weld because the gas flow provided by the arc torch could deflect the plasma induced by the laser and so modify the absorption of laser beam. This angle of electrode to the top surface of the workpiece is often set at around 40-60 degrees. Indeed in order to ensure maximum penetration, the laser beam must be as perpendicular as possible to the surface of workpiece, so the angle is inexistent. Nevertheless if the metal has an high reflectivity the laser beam could be reflected inside the laser head and damage the optical fiber 
(Rasmussen \&Dubourg, 2005), so many studies use an angle of laser beam, that must be different from the electrode's angle.

Fig. 3. Laser-arc distance

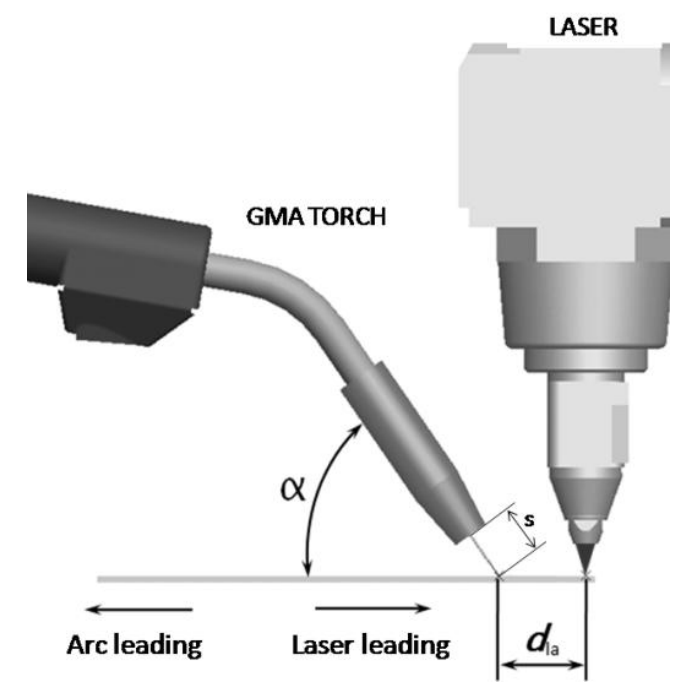

High welding speed is an advantage of hybrid welding process and it's strictly related to the penetration. The weld penetration increases when the welding speed decreases because the heat input per unit length of weld is higher. The gap filling capability is improved at lower welding speeds (at constant filler wire feeding). The ratio between welding speed and filler wire feeding is important for the stability of the keyhole and thus for the stability of the process itself. On the other hand a high travel speed of hybrid welding processes lead to a fast heating and cooling cycle in the workpiece, and so many metallurgical defects could appear in weld fusion zone. A too low welding speed increases the penetration but enlarges the molten zone until the limit of burn through the metal. Moreover the optimal welding speed grows up with the increase of the gap, because with a bigger gap the heat input in the metal becomes lower (Nielsen et al., 2002). In the laser-arc welding, the laser power is the main heat sources for the improving of welding efficiency because of the appearance of laser keyhole and deep penetration process (Gao et al., 2006). The ratio of the power of the two sources, obtained by dividing the arc power for the laser power is an important factor in hybrid welding; the geometry and the metallurgical properties of the joint strictly depend on the balance between the influences of the laser source and arc source. For hybrid weldsincreasing the energy ratio of laser to arc can narrow the weld width, reduce the tendency of grain growth and modify the microstructure of fusion zone. The hybrid weld withlow energy ratio has a softened HAZ while high energy ratio has notbecause of low line energy. At constant feed rate of filler metal and laser power, a higher power arc causes an increase of the width of the bead until it reaches a maximum value. Over this limit the width decreases or remains constant, depending on the wire feed speed(El Rayes et al., 2004). This behavior is mainly due to the fact that the power of the arc is increased by increasing the voltage and maintaining a constant wire feed speed, so the arc length and its diameter grow up and consequently the area of molten pool grows up. After the maximum bead width has been obtained, a further increase of arc power causes a further enlargement of the 
molten pool, but the melted metal which is deposited probably will not be enough to fill that area. In addition an enhancement of arc power causes a reduction of the penetration owed by the arc source, because changes the base metal transfer mode. So in order to emphasize the deep penetration of the laser beam, the power of arc needs to be controlled with regards to the metal transfer mode that must be preferably pulsed/spray and not short/globular-arc. Under appropriate welding parameters, hybrid welding with high energy ratio can ensure higher welding speed better weld shape and more sound mechanical performance with respect to laser weld.

\section{Laser-arc welding state of the art research - Aluminium \&Magnesium alloys}

One of the purposes of experimental analysis of the hybrid laser arc welding process is the characterization of applicability of the process to different materials and the research of welding process windows. In hybrid Nd:YAG laser/MIG welding, with Argon as shielding gas, of high strength aluminum alloys AA2024-T3 and AA7075-T6 with 1-2mm of thickness, a large number of transverse cracks were found in the weld fusion zone (Hu\&Richardson, 2006). In order to understand the cracking mechanism, a constitutive modeling of thermal and thermo-mechanical behavior has been built. The cracking is related to the elongated temperature distribution in the welding direction, which induces a transverse tensile strain in the weld fusion zone during the cooling phase. In detail, the number of cracks increases with an increase of welding power and increases with the increase of travel speed. The proposed solution is use an additional heat source to alter the temperature distribution and thus reduce the cracking tendency.Magnesium alloy AZ31B is a material with a low absorptivity; this characteristic causes many problems during laser welding because most of the laser energy is reflected during the process. Researchers (Song et al., 2006) studied the effects of key welding parameters such as welding speed, defocusing distance, and laser-to-arc distance on overlap weldability of magnesium alloys sheet and obtaineddefect-free joints whose shear strength was up to $80 \%$ of that of the base metal. An interesting result is the high influence of welding speed on the bead cross-section. They suggest that hybrid overlap joints can be divided into two parts: a laser alone acting zone and a laser-arc hybrid zone. These zones are made by different grain size depending on the different characteristics of the heat sources.Another key process parameter, which can modify the resultant microstructure of a hybrid laser-arc joint, is the composition of the welding wire, which resolves many welding problems such as solidification cracks during the Aluminum alloys welding.The effect of welding wires on microstructure and mechanical properties of $2 \mathrm{~A} 12$ Aluminum alloy in $\mathrm{CO}_{2}$ laser-MIG hybrid welding were evaluated (Yan et al.,2009). Several plates of 2A12 aluminum alloy were butt welded by ER4043 and ER2319 welding wires, respectively, producing penetration joints without any defects. The analysis of the phase composition using X-ray diffraction and scanning electron microscopy allowed studying the microstructure, segregation behaviors of major alloying elements and the formation of eutectics at dendrite boundaries in the joints. Tensile test showed that the joint efficiency by ER2319 and ER4043 welding wires reached up to $78 \%$ and $69 \%$, with a transgranular 
type of failure (Huang et al., 2008).Casalino \& Lobifaro (Casalino \& Lobifaro, 2005) investigated5005 and $5052 \mathrm{Al}-\mathrm{Mg}$ alloyswelding. $\mathrm{CO}_{2}$ laser and MIG arc sources were used simultaneously. The MIG-arc-to-laser-beam distance and the gun-tilting angle varied. The former variation in distance permitted to compare coupled and combined working conditions. The metallurgical and technological characterizations of $\mathrm{CO}_{2}$ Laser-MIG combined welding of $\mathrm{Al}-\mathrm{Mg}$ alloy sheets were performed on bead-on-plate welds, which were either $3 \mathrm{~mm}$ and $10 \mathrm{~mm}$ thick (Casalino et al, 2005).

\section{Laser-arc welding state of the art research - Stainless Steels}

With respect to the properties of austenitic stainless steel (ASS) weld, many studies were carried out during the last years (Hauser \& Vanecho, 1982; Delong, 1974; Hall \& Briant, 1984; Folkhard, 1988). Austenitic stainless steel is weldable by conventional welding processes in spite of their sophisticated metallurgy. Nevertheless some problems arise due to the crystal boundary corrosion, stress corrosion and hot cracking in the weld bead (Lippold \& Savage, 1982; Brooks et al., 1984). Multipass hybrid welding of austenitic stainless steel AISI304 using the lowpower Nd: YAG laser-MAG arc hybrid welding method was studied (Huang et al., 2008). They qualify the effects of multipass hybrid welding on ASS microstructure, phase composition, weld postheat influence, and weld bead precipitated phase. Hybrid welding process is characterized by a high welding speed and the permanency of the molten metal at high temperature is short. So the solidification rate of molten metal changes quickly. High solidification rate implies a fine microstructure and minimal micro segregation. Unfortunately the solidification rate is variable along the joint. So the partition coefficient between ferrite and austenite in the weld metal depends on the distance from top surface. In particular the weld metal phase at $3 \mathrm{~mm}$ from the top of the weld beam surface suffers a notable modification that corresponds to an evolution of the partition coefficients toward the parent metal values due to the influence of postweld heat input of the multipass process. The results show that sound welded joints without any solidification and shrinkage defects could be obtained after welding, with a corrosion resistance equivalent to that of the parent metal. In addition several researches (Yan et al., 2010) focus on the analysis of the microstructure and mechanical properties of stainless steel joints by tungsten inert gas (TIG) welding, laser welding and laser $\mathrm{CO}_{2}$-TIG hybrid welding. The results for a $3 \mathrm{~mm}$ thick 304 stainless steel show that the joint by laser welding have highest tensile strength and smallest dendrite size in all joints, while the joint by TIG welding has lowest tensile strength and biggest dendrite size (Yan et al., 2010). Transition zone and HAZ are present in TIG joint, while they are absent in hybrid and laser joints. The dendrite size in TIG joint is larger than in laser and hybrid joints. The laser joint shows the smallest dendrite size in all joints. The tensile strengths of TIG joint, laser joint and hybrid joints are 560,733 and $683 \mathrm{Mpa}$, respectively. So the hybrid welding results are suitable for welding 304 stainless steel. Moreover laser Nd: YAG-TIG hybrid welding of very thin 316L stainless steel sheets $(0.4-0.8 \mathrm{~mm}$ thick) in a butt joint configuration has been studied (Arias et al., 2005). The laser melted pool stabilizes the TIG arc, and a laser trailing arrangement allows welding 
speeds until $15 \mathrm{~m} / \mathrm{min}$. In order to find the optimal process parameters, during the experiment the laser power has been increased such as the arc current has been contemporary decreased. Full penetration joints with enough width to absorb small cut edge defects or misalignments between the two sheets have been produced and in order to avoid thermal distortions and excess fusion the TIG current has been minimized and an additional shielding gas, such as Ar, has been used. In order to overcome the high level of distortion deriving from traditional welding processes applied to a duplex stainless steel, several investigations have been achieved (Vandewynckèle et al., 2007). In fact duplex stainless steels are of great interest for shipbuilding and chemical industry because of their good corrosion resistance. Unfortunately duplex stainless steel has a high coefficient of expansion which induces high welding distortion. Using laser welding allows to reduce welding deformations but, because of the high cooling rates, causes the formation of ferrite grains and so reduces the corrosion resistance properties of metal base. The challenge is, using hybrid laser Nd: YAG-MAG welding, to find a compromise between a low level of distortions and a concentration of ferrite and austenite as near as possible to the metal base. The micro structural examinations of $12 \mathrm{~mm}$ thick butt joint of 2205 duplex stainless steel show the possibility to obtain good quality butt joints with a ferrite/austenite ratio in the range of $25 \%$ to $70 \%$. This target could be achieved slowing the heat input enough to enable the formation of austenitic grains.

\section{Laser-arc welding state of the art research - Mild and high strength steels}

Among the process parameters affecting the quality of a hybrid welded joint, the shielding gas has an important role(Gao et al., 2007). A detailed experiment of $\mathrm{CO}_{2}$ laser-TIG hybrid welding with different shielding gas was carried out on an AISI316L stainless plate. The results demonstrate that the plasma shape is really influenced by laser-arc plasma interaction and the gas flowing direction and velocity, and varies with the shielding gas parameters; moreover penetration could varies considerably using a trailing paraxial nozzle, a leading paraxial nozzle or a coaxial nozzle. A larger percentage of He content in shielding gas is strictly related to an amount of the laser energy absorbed by workpiece. The combination of two different shielding gases with different flows from different nozzles, coaxial and paraxial in particular, ensures the deeper penetration. A study of microstructures has been finalized to understand laser-arc hybrid welding influences on mild steel. The authors (Gao et al., 2008)investigate the effects on microstructure of a hybrid laserCO $\mathrm{CO}_{2}$-MIG welding with an arc leading arrangement and a bead-on plate joint configuration. The authors classify a typical hybrid weld in two parts: the wide upper zone and the narrow nether zone, which are defined as arc zone and laser zone, respectively. These zones have evident differences in term of microstructure, alloy element distributions and micro hardness. Laser zone has a finer grain size with respect to arc zone, a higher micro hardness and lower alloy element content. These differences are guided by the temperature gradient, crystallizing and effects of arc pressure on the molten pool between laser zone and molten zone. At constant arc current with the increase of laser power the depth of laser zone of hybrid weld increases and made the wine-cup 
shape. Otherwise at constant laser power, the increasing arc current enhances both the width and the depth of arc zone, but a too large arc current could decrease the penetration depth of laser keyhole because ofstrong arc plasma, which disrupts the synergetic effects between laser and arc. In this study a 180A arc current and a laser power between 3.5 and $4.5 \mathrm{~kW}$ were fixed as good parameters for a full penetration and a wine-cup shape of hybrid weld.A detailed study of the weldability of ultra-fine grained (UFG) steel SS400 has been carried out (Gao et al., 2009) with detailed experiments about laser $\mathrm{CO}_{2}$-TIG hybrid welding; the focus is to investigate the effects of welding parameters on weld shape, microstructure, grain growth in heataffected zone and mechanical performance. In this study the arc current is constant and the laser power is variable. So the energy ratio of laser to arc is variable. If energy ratio is constant, a too low welding speed causes the breakout defect of weld, a too high welding speed fails to obtain a full penetrated weld. At different ratios of laser to arc energy, the selected welding speed used for butt joint has been the highest compatible with a full penetrated weld. Therefore, the highest ratio guarantees the highest welding speed and the smallest heat input per unit length along welding direction. The results of microstructure analysis show that an hybrid process with an high ratio of laser to arc energy is really similar to a laser welding process, so an harder structure could be achieved, such as martensite or bainite and fine grain in fusion zone and restrain the grain growth of coarse-grained region in HAZ. If the ratio is low the hybrid process is similar to arc welding and only coarse grain pearlite and ferrite with low microhardness in fusion zone, as well as a wider ferrite coarsening region in HAZ could be obtained. Hybrid welding distinguishes from laser welding for the gap bridging capability, fundamental characteristic to achieve high productivity and good weld quality. So a research has been pointed on the optimization of the main process parameters related to a laser $\mathrm{CO}_{2}-\mathrm{MAG}$ source, such as wire diameter and feed rate, voltage, contact tip to workpiece distance, and high speed arc rotation in constant voltage mode in a butt welding of an $8 \mathrm{~mm}$ thick mild steel (Chae et al., 2005). Fixed process parameters are focal length, torch angle, welding speed, shielding gas and distance between laser spot and electrode. The experiment was performed varying welding current and voltage, contact tip to workpiece distance and gap. Moreover an arc rotation mechanism has been implemented to fulfill gap requirements up to $2 \mathrm{~mm}$ and ensure gap bridgeability without a contact tip to workpiece regulation. The results show a complete control of the process up to $2 \mathrm{~mm}$ joint gap. Nevertheless, several geometric imperfections have focused the attention on the complexity of the parameters control. Therefore many investigations are still in progress to overcome the problem of gap tolerance.As previously mentioned the hybrid laser-arc process could be realized using a laser leading or an arc leading arrangement. Nowadays a big part of the tested hybrid process are laser leading; however use a laser leading or an arc leading process depends on several factors, such as metal base characteristic, power of laser source, type of arc source.The laser hybrid welding, with arc leading, of HSLA-590 steel has been studied using $2.4 \mathrm{~kW} \mathrm{CO}$ laser and 350A MAG welding machine (Liu \& Kutsuna, 2005). This research is focused on the effects of the leading process, MAG current and welding speeds on the microstructure and the hardness distribution in 
welds. The first result is that penetration and bead width change with the different leading arrangement.Subsequently the influence of MAG current on bead width has been evaluated; so the bead width increases with the increase of the MAG current. At the same time the penetration increases and then decreases with the increase of MAG current. This phenomena could be explained by the interaction of the formed plasma above the molten pool that expands with the expansion of molten pool, which absorbs some of the laser beam energy when the laser beam thrusting the plasma; moreover, the deposited metal of MAG increases with the increasing of MAG welding current and arc voltage, so the reinforcement height increases, so the laser beam must thrust the deposited metal and then arriving at the base metal.Therefore, the energy arriving at base metal decreases with the increasing of MAG current, and also the penetration decreases at the same time. The authors studied also the effect of welding speed on penetration. The penetration decreases with the increasing of welding speed. Nevertheless from the view of points of jointed area in unit of time, the joining speed at $1 \mathrm{~m} / \mathrm{min}$ welding speed is three times higher than that at $0.2 \mathrm{~m} / \mathrm{min}$ welding speed. The microstructure results show that the hybrid welding is useful to increase the toughness of microstructure, such as ferrite and bainite, compared with laser welding and MAG welding individually under the same welding speed. Nevertheless the measure of the hardness of weld shows that the weld metal hardness of hybrid welds is lower than that of laser welds and MAG welds. A relevant problem of high strength steel is the high alloy content which causes several problems such as crack, porosity and insufficient dynamic property of weld joint. In order to understand these problems, a study has been pointed on the characteristics of weld in laser and hybrid laser Nd: YAG-MIG welding (Lee et al., 2005). In this investigation the variable process parameters were the joint gap, the distance between laser spot and arc source and the energy input. Analyzing frequency and amplitude of wave forms hybrid process, the authors find a more stable metal transfer mechanism with respect of MIG welding, because of stabilization effects of laser induced plasma. Moreover the molten drop melting rate is higher than MIG welding even though at the same wire feeding rate. The results show a penetration depth increased by laser-MIG hybrid welding. A further research on hybrid laser-arc welding for an high strength steel with a thickness up to $16 \mathrm{~mm}$ (Coste et al., 2005) shows a comparison of the performances obtained with laser Nd:YAG welding (with cold wire) and hybrid welding (laser-MAG). The relative application is welding of large diameter storage tank and prefabrication of pipeline; the thickness is variable, so the contribute of MAG welding is really important. The authors build a workstation with a seam tracking sensors, controlling the welding head position and measuring the volume to be filled (and so calculate the wire feed), and a twin spot laser source. A good setting of parameters and their optimization joined with multipass process guarantees an improvement of $50 \%$ in term of welding speed and an higher quality when using hybrid technique compared to laser alone one. In order to increase welding performances and weldability of high strength steel with a thickness up to $30 \mathrm{~mm}$ the laser-MAG hybrid welding has been deeply investigated (Petring et al., 2007). $\mathrm{CO}_{2}$ laser up to $20 \mathrm{~kW}$ and $\mathrm{Nd}$ :YAG up to $7.2 \mathrm{~kW}$ were parts of the research equipment. The welding head, deriving from previous studies (Petring et al., 2003), integrated 
hybrid welding nozzle. The head contained a single water cooled nozzle for laser and arc and a system for a stable guiding of the wire electrode. Several process rules have been established for parameter settings like focal position, laser-arc orientation, laserarc distance, welding speed, wire feed rate. the optimizationthe process parameters finalized and the limit of gap bridgeabilitywerethe targets. Moreover special techniques weredeveloped to overcome the limit and reach a thickness of $30 \mathrm{~mm}$. In addition a special seam shaping technique with high power Nd:YAG laser and radial jet nozzle was developed to ensure symmetrical welds with a two sided approach. A laser-dual MAG hybrid system allowed to weld in single pass from both side simultaneously. This study has reinforced the knowledge about hybrid laser-MAG welding and showed new the potentialities for the hybrid welding.

\section{Laser-arc welding state of the art research - Heterogeneous materials}

The joint of different materials is today a challenge in the field of hybrid.Very often the formation of intermetallic phases supports cracking phenomena in the regions where the composition is modified. An aluminum-magnesium-silicon alloy 6061 and a magnesium-aluminum-zinc alloy AZ31B has been joined with an overlap configuration by the laser-TIG hybrid welding process (Liu et al., 2006). In order to overcome the cracking an interlayer of cerium, between $\mathrm{Mg}$ alloy and $\mathrm{Al}$ alloy, has been utilized. The layer of Ce reveals useful to uniform and purify the microstructure of the fusion zone. Nevertheless the addition of Ce doesn't prevent the presence of intermetallic phases, but micro structural analysis shows the absence of cracks and an improved strength and hardness of joints using $\mathrm{Ce}$ as interlayer. A subsequent research (Casalino \& Rella, 2007) investigates the weldability of a copper aluminum alloy to an austenitic stainless steel AISI 308 through a MIG-LaserCO $\mathrm{CO}_{2}$ combined heat source. The challenge is overcome the differences of melting point, the low solubility of iron in aluminum and the formation of brittle intermetallic compounds. The aim of the study is limit the contemporaneous fusion of the steel and the aluminum using a combined source system with two degrees of freedom, and so produce a thinner as possible interface layer as result of diffusion and local fusion phenomena. The weld thickness is $3.2 \mathrm{~mm}$ and variable process parameters are power of laser, welding speed, the distance between laser and arc along the welding direction, the distance between laser and arc in transverse direction. This technique produce several defects like irregular aluminum-steel interface, fragments, protrusion of steel in the aluminum matrix and small cracks in the layer interface. Consequently the mechanical characteristics of the weld are really low. Nevertheless further investigations can be undertaken to understand the mechanisms of dissimilar materials welding using hybrid laser-arc welding.

\section{Industrial applications of laser-arc hybrid welding}

Advantages of hybrid welding over laser welding include an increased welding speed, higher process stability, higher gap bridgeability, deeper penetration, lower capital investment costs and greater ductility. Advantages of hybrid welding over arc 
welding include higher welding speeds, deeper penetration at higher welding speeds, lower thermal input, higher tensile strength and narrower weld-seams. From an economic point of view, the hybrid process allows to reduce the laser power. To sum up this technology, if compared to laser or arc welding, ensure at the same time high productivity and low welding cost. Nevertheless a hybrid welding system requires high investment costs, so nowadays is adopted into the industrial fields focused on short fabrication times, low manufacturing costs, high productivity and high technical performances. In automotive hybrid laser-MIG welding technique is today employed by many car industries (Staufer, 2005). A laser hybrid process is adopted for welding the doors of the VW Phaeton, in particular lap joints and butt joints for the extruded sections, castings and sheets made from aluminium. The Audi A8 vehicle includes about $4.5 \mathrm{~m}$ of weld seams; the hybrid welding is used in the area of the lateral roof frame that is equipped with various functional sheets. For the axle production of Daimler, an hybrid laser welding process was chosenin order to increase welding speed (about 30\%), maintaining good penetration and high metallurgical properties. side advantages were the reduction of space in the shop floor and a high wire efficiency (Staufer, 2007). The hybrid welding process is of great interest for shipbuilding industries all over the world (Jasnau et al., 2002). The German shipyard Meyer-Werft realized an industrial application of the laser-GMA-hybrid welding process with a $\mathrm{CO}_{2}$-laser for the welding of panels with geometry of $20 \times 20 \mathrm{~m}$ and a low thickness. The Italian Fincantieri also uses the hybrid welding technique (Gerritsen et al., 2005); in order to reduce distortion and overcome the bridgeability issues with the expected standards of shipbuilding industry, several procedures have been developed for Nd:YAG laser-MAG hybrid welding of $\mathrm{T}$ joints. Among the technical problems, the formation of porosity, caused by the shop primer (used in shipbuilding industries) which coats the steel surface to prevent corrosion, has been investigated in literature (Hong \& Lee, 2005). On the other hand, many studies focus on the high automation potentialities of hybrid welding process (Olschok et al., 2007). Hybrid welding allows significant time and cost savings by the reduction of multi-pass requirements, with the advantage of the deep penetration offered by this process. Many investigations have been undertaken about weldability of materials, such as supermartensitic stainless steels (Walz et al., 2001) and about the effectiveness of cost reduction offered from hybrid techniques (Reutzel et al., 2006) for pipelines industries. Because of their low density, the light metals based on aluminium, magnesium, titanium are particularly attractive for aerospace and aviation industry. In these applications, strength and fatigue resistance are crucial, so many research are focused on this characteristics (Vaidya et al., 2006). Thick aluminium alloys up to $12 \mathrm{~mm}$ has been successful butt jointed using Nd:Yag-MIG hybrid process and a high power laser fibre-MIG hybrid process (Allen et al., 2006). So in this application the high quality of hybrid welds has proved profitable. This technique is in particular of great interest for these industries when dealing with titanium alloys. Today using a fibre laser coupled with an arc source, high quality welds of CP-Ti sheets of $1.5 \mathrm{~mm}$ thickness are feasible with a speed up to $9 \mathrm{~m} / \mathrm{min}$ (Li et al., 2009). High welding speed and deep penetration are crucial in the power generation construction field because of the need of weld thick plates controlling gap and groove tolerances. A $20 \mathrm{~mm}$ thick austenitic stainless steel can be welded using Nd:YAG laser coupled with an arc source with multi-pass technique (Jokinen \& Kujanpa, 
2003). Nowadays the challenge is a continuous development of welding techniques which can yield fewer passes, less welding time and lower distortion while respecting the tolerance requirements. The other possible applications of hybrid processes are related to rail transport industry, bridges fabrication and chemical plants. In all these fields hybrid welding shows superior features compared to laser welding and it's slowly taking its place within these industries. Of course these are just a few applications of the hybrid welding process, which in current years is in a full phase of progress.

\section{Conclusion}

Today hybrid welding techniques promise to be high productivity technologies. Welding speed, capacity for gap bridging, low thermal load, high thickness, weld quality and decreasing running costs are some advantages. Nevertheless the combination of two processes is a challenge because of increasing physical complexity and the relative setting of several process parameters. The interaction between two different heat sources needs a deep understanding to control the process. Nowadays in literature there are a lot of discrepancies about the advantages and disadvantages of the hybrid processwhich is the consequence of a still partial knowledge of the process related to the mutual interaction between parameters still partially unknown.Hybrid laser-arc welding can significantly impact in a large number of industries as it can improve weld quality, production rate, cost savings and affect construction methods, production paradigms and business economics.In this work the review of a number of researches on hybrid laser-arc welding has been presented along with the updated applications in the industry. This study represents a state of the art, which is still in progress thank to the continuous technical and scientific improvements.Future scientific investigations will be focused on the improvement of the potentialities of hybrid laser welding through the deep investigation on the interaction and correlation between the laser beam and the arc and their effects on the final weld. Thanks to the rapid development in the sector, the authors figure out that a new review will be necessary in few years.

\section{References}

Allen, C.; M., Verhaeghe, G. P., Hilton, A., Heason, C. P., Prangnell, P. B. (2006). Laser and hybrid laser-MIG welding of 6.35 and $12.7 \mathrm{~mm}$ thick aluminium aerospace alloy, International Conference on Aluminium Alloys (ICAA 10), Vancouver, Canada, 9-13 July 2006

Arias, J. L.; Romero, P., Vandewynckèle, A., Vázquez, J. (2005). Laser-tig hybrid welding of very thin austenitic stainless steel sheets,Laser Materials Processing ConferenceICALEO2005 Congress Proceedings, pp.104-107, Miami(FL), USA Nov. 2005, LIA

Bagger, C. \& Olsen, F.O.(2005). Review of laser hybrid welding, J. Laser. Appl., Vol.17 (Febr. 2005) pp.2-14, ISSN 1042-346X

Beck, M.; Berger, P., Hugel, H. (1995). The effect of plasma formation on beam focusing in deep penetration welding with $\mathrm{CO}_{2}$ lasers, Journal of Physics D: 
Appl. Physics, Vol.28, No.12, (14 December 1995), pp.2430-2442, ISSN 0022-3727

Beyer, E.; Imholff, R., Neuenhahn, J., Behler, K.(1994). New aspects in laser welding with an increased efficiency,Laser Materials Processing Conference ICALEO'94Congress Proceedings, pp.183-194, Orlando(FL), USA, 1994, LIA

Brooks, J.A.; Thompson, A.W., Williams, J.C. (1984). Fundamental Study of The Beneficial Effects of Delta Ferrite in Reducing Weld Cracking, Welding Journal, Vol.63, No.3, pp.71-83, ISSN 0043-2296

Campana, G.; Fortunato, A. , Ascari, A., Tani, G., Tomesani, L. (2007). The influence of arc transfer mode in hybrid laser-mig welding, Journal of Materials Processing Technology, Vol.191 (August 2007), pp.111-113, ISSN 0924-0136.

Casalino, G. \&Lobifaro, F. (2005). Process parameters effects on Al-Mg MIG-Laser $\mathrm{CO}_{2}$ welding.ICALEO 2005 Congress Proceedings, pp. 190-195, Miami (FL), USA, Nov. 2005, LIA

Casalino, G., Ludovico A., Chieco, G. (2005). Characterisation of Al-Mg alloys MIG-laser $\mathrm{CO}_{2}$ combined welding, ICALEO2005 Congress Proceedings, pp.1062-1068, Miami (FL), USA,Nov. 2005, LIA

Casalino, G. \& Rella, C. (2007). MIG-laser combined welding of aluminum alloy to 304 stainless steel, Laser Materials Processing Conference ICALEO2007 Congress Proceedings, pp.287-292, Orlando (FL), USA, Oct. 29-Nov. 1, 2007, LIA

Chae, H.; Kim, C., Kim, J., Rhee, S. (2005). The effect of process parameters on the gap bridging capability for $\mathrm{CO}_{2}$ laser-gma hybrid welding, Laser Materials Processing Conference ICALEO2005 Congress Proceedings, pp.169-173, Miami (FL), USA ,Nov. 2005, LIA

Coste, F.; Fabbro, R., Allais, C., Mas, J.P. (2005), Laser and hybrid welding of high strength steel application to pressure vessel manufacturing, Laser Materials Processing ConferenceICALEO2005 Congress Proceedings, pp.174-182, Miami(FL), USA, Nov. 2005, LIA

Delong, W.T.(1974). Ferrite in Austenitic Stainless Steel Weld Metal, Welding Journal, Vol.53, No.7, pp.273-286, ISSN 0043-2296

Dilthey, U. \& Wieschemann, A. (1999). Prospects by combining and coupling laser beams and arc welding processes, Rivista Italiana della Saldatura, Vol.52, No.6, (Nov.-Dec. 2000), pp.749-759, ISSN 0035-6794

Dilthey, U.; Lueder, F., Wieschemann, A. (1999). Technical and Economical Advantages by Synergies in Laser Arc Hybrid Welding, Welding in the World, Vol.43, April 1999, pp.141-152, ISSN 0043-2288.

El Rayes, M.; Walz, C., Sepold, G. (2004), The Influence of Various Hybrid Welding Parameters on Bead Geometry, Welding journal, Vol.83, No.5, May 2004, pp.147-S-153-S, ISSN 0043-2296

Folkhard, E. (1988). Welding Metallurgy of Stainless Steels, Springer-Verlag, ISBN 0387820434, New York

Gao, M.; Zeng, X.Y., Hu, Q.W. (2006). Effects of welding parameters on melting energy of $\mathrm{CO}_{2}$ laser-GMA hybrid welding, Science and Technology of Welding \& Joining, Vo.11, No.5,(Sept. 2006), pp.517-522, ISSN 1362-1718 
Casalino, G.; Dal Maso, U.; Angelastro, A. \& Campanelli, S.L.: Hybrid Laser Wel...

Gao, M.; Zeng, X., Hu, Q. (2007). Effects of gas shielding parameters on weld penetration of $\mathrm{CO}_{2}$ laser-TIG hybrid welding, Journal of Materials Processing Technology, Vol.184, pp.177-183,ISSN0924-0136

Gao, M.; Zeng, X., Yan, J., Hu, Q. (2008). Microstructure characteristics of laserMIG hybrid welded mild steel, Applied Surface Science, Vol.254, No.18, (8 March 2008), pp.5715-5721, ISSN 0169-4332

Gao, M.;Zeng, X., Hu, Q., Yan, J. (2009). Laser-TIG hybrid welding of ultra-fine grained steel, Journal of Materials Processing Technology, Vol.209, (Febr. 2008) pp.785-791, ISSN 0924-0136

Gerritsen, C. H. J.; Weldingh, J., Klæstrup Kristensen, J. (2005). Development of Nd:Yag Laser-MAG hybrid welding of T joints for shipbuilding, NoLAMP 10 (10th Nordic Laser Materials Processing Conference), 17-19 August 2005, Lulea, Sweden.

Graf, T. \& Staufer, H. (2003). Laser-Hybrid Welding Drives VW Improvements, Welding Journal., Vol.82, No.1, pp.42-48, ISSN 0043-2296

Hall, E.L. \& Briant, C.L. (1984). Chromium Depletion in the Vicinity of Carbides in Sensitized Austenitic Stainless Steels, Metallurgical and Materials Transactions A, Vol.15, No.5, pp.793-811, ISSN 1073-5623

Hauser, D. \& Vanecho, J.E. (1982). Effects of Ferrite Content in Austenitic Stainless Steel Welds, Welding Journal, Vol.61, No.2, 1982, pp 37-44, ISSN 0043-2296

Hong, S.G., \& Lee, J.B. (2005). Effects of hybrid welding parameters on porosity formation in C-Mn steel for shipbuilding,Laser Materials Processing Conference ICALEO2005 Congress Proceedings, pp.183-189, Miami(FL), USA, Nov. 2005, LIA

Hu, B.\& Richardson, I.M. (2006). Mechanism and possible solution for transverse solidification cracking in laser welding of high strength aluminium alloys, Materials Science and Engineering, Vol.429, No.1-2, (15 August 2006), pp.287-294, ISSN 0921-5107

Huang, R. S.; Kang, L., Ma, X. (2008). Microstructure and Phase Composition of a Low-Power YAG Laser-MAG Welded Stainless Steel Joint, Journal of Materials Engineering and Performance, Vol.17, No.6, (March 2008), pp.928935, ISSN 1059-9495

Ishide, T.; Tsubota, S., Watanabe, M. (2002). Latest MIG, TIG, arc-YAG laser hybrid welding systems for various welding products, First International Symposium on High-Power Laser Macroprocessing, Vol.4831, pp.347-352, Japan, 27-31 May 2002, Proc. SPIE(International society for optical engineering), Osaka

Ishide, T.; Tsubota, S., Watanabe, M., Ueshiro, K.(2003). Development of TIG-YAG and MIG-YAG hybrid welding, Welding International, Vol.17, No.10, pp.775780, ISSN 0950-7116

Jasnau, U.; Hoffmann, J., Seyffarth, P. (2002). Nd:YAG-laser - gas metal arc hybrid welding: a chance for the use of the advantages of laser technology and flexible automation in shipbuilding and steel construction, Paper and presentation for the RWIA'2002-2002 International Conference on Robotic Welding, Intelligence and Automation; December 9-12, 2002, Shanghai. 
Jasnau, U.; Hoffmann, J., Seyffarth, P. (2004). Nd:YAG-laser-GMA-Hybrid Welding in Shipbuilding and Steel Construction, Robotic Welding Intelligence and AutomationSpringer, New York, ISBN 3-540-20804-6, pp.14-24

Jokinen, T.\& Kujanpa, V.(2003).High power Nd:YAG laser welding in manufacturing of vacuum vessel of fusion reactor, Fusion Engineering and Design, Vol.69, (2003), pp.349-353, ISSN 0920-3796

Kutsuna, M. \& Chen, L. (2002). Interaction of Both Plasmas in $\mathrm{CO}_{2}$ Laser-MAG Hybrid Welding of Carbon Steel, FirstInternational Symposium on HighPower Laser Macroprocessing, Vol.4831, pp.341-346, 27-31 May 2002, Proc. SPIE(International society for optical engineering), Osaka, Japan

Lee, M.; Chang, W., Kweon, Y., Lee, D.(2005). Laser-MIG hybrid weldability of high strength steel for car industry,Laser Materials Processing Conference ICALEO2005 Congress Proceedings, pp.134-142, Miami(FL), USA,Nov. 2005, LIA

Li, C.; Muneharua, K., Takao, S., Kouji, H. (2009). Fiber laser-GMA hybrid welding of commercially pure titanium, Materials and Design, Vol.30, pp.109-114 ISSN 0261-3069

Lippold, J.C. \& Savage, W.F. (1982). Solidification of Austenitic Stainless Steel Weldments-part.3:The Effect of Solidification Behavior on Hot Cracking Susceptibility, Welding Journal, Vol.61, No.2, pp.388-396, ISSN 0043-2296

Liu, L.; Liu, X., Liu, S. (2006). Microstructure of laser-TIG hybrid welds of dissimilar $\mathrm{Mg}$ alloy and $\mathrm{Al}$ alloy with $\mathrm{Ce}$ as interlayer, Scripta Materialia, Vol.55 (April 2006), pp.383-386, ISSN 1359-6462

Liu, Z. \& Kutsuna, M. (2005). Metallurgical study on laser-mag hybrid welding of HSLA-590 steel,Laser Materials Processing Conference ICALEO2005 Congress Proceedings, pp.127-133, Miami (FL), USA ,Nov. 2005, LIA

Magee, K. H.; V. E. Merchant, C. V. Hyatt, (1990). Laser assisted gas metal arc weld characteristics,Laser Materials Processing Conference ICALEO'90Congress Proceedings, pp.382-389, Boston, USA, Nov 4-9 1990,LIA

Nielsen, S.E.; Andersen, M.M, Kristensen, J.K., Jensen, T.A. (2002). Hybrid welding of thick section C/Mn steel and aluminium, Meetings of IIW Commission XII during International Institute of Welding Annual Assembly, Vol.15, (26-28 June 2002), Copenhagen, Denmark.

Olschok, S.; Reisgen, U., Dilthey, U.(2007). Robot application for laser-GMA hybrid welding in shipbuilding,Laser Materials Processing Conference ICALEO2007 Congress Proceedings, pp.308-315, Orlando (FL), USA, Oct. 29 - Nov. 1, 2007, LIA

Petring, D.; Fuhrmann, C., Wolf, N., Poprawe, R. (2003). Investigations and Applications of Laser-Arc Hybrid Welding from Thin Sheets up to Heavy Section Components, 22nd International Congress on Applications of Lasers and Electro Optics ICALEO2003 Congress Proceedings, pp.1-10, October 1316, Jacksonville(FL), USA, LIA

Petring, D.; Fuhrmann, C., Wolf, N., Poprawe, R., (2007). Progress in laser-MAG hybrid welding of high-strength steels up to $30 \mathrm{~mm}$ thickness,Laser Materials Processing ConferenceICALEO 2007Congress Proceedings, pp.300-307, Orlando (FL), USA, Oct. 29-Nov. 1, 2007, LIA 
Casalino, G.; Dal Maso, U.; Angelastro, A. \& Campanelli, S.L.: Hybrid Laser Wel...

Rasmussen, D.\& Dubourg, L. (2005). Hybrid laser-GMAW welding of aluminium alloys: a review, Proceedings of the 7th International Conference on Trends in Welding Research, pp.133-142, Callaway Gardens Resort, Pine Mountain (May 16-20, 2005), Georgia, USA

Ready, J.F. (1997). Industrial Applications of Lasers, 2nd edition, Academic press, ISBN 0125839618, London

Reutzel, E.W.; Sullivan, M.J., Mikesic, D.A., (2006). Joining Pipe with the Hybrid Laser-GMAW Process: Weld Test Results and Cost Analysis, Welding Journal, (June 2006), pp.66-71, ISSN 0043-2296

Seyffarth, P. \& Krivtsun, I. V. (2002).Laser-arc processes and their applications in welding and material treatment, Taylor \& Francis , ISBN 9780415269612, London

Song, G.; Liu, L., Wang, P. (2006). Overlap welding of magnesium AZ31B sheets using laser-arc hybrid process, Materials Science and Engineering, Vol.429, No.1-2, (12 May 2006), pp.312-319, ISSN 0921-5107

Staufer, H.(2005). LaserHybrid Welding and LaserBrazing: State of the Art in Technology and Practice by the Examples of the Audi A8 and VW-Phaeton, Proceedings of the 3rd International WLT Conference on Lasers in Manufacturing (2005), pp.203-208.

Staufer, H.(2007). Laser Hybrid Welding in the Automotive Industry, Welding Journal, October 2007, pp.36-40, ISSN 0043-2296

Steen, W.M. (1980). Arc augmented laser processing of materials, J. Appl. Phys, Vol. 51, No.11, (Nov 1980) pp.5636-5641, ISSN 0021-8979

Steen, W. M.(2003). Laser material processing, 3rd edition, Springer, ISBN 1852336986, London

Vaidya, W. V.; Angamuthu, K., Koçak, M., Grube, R., Hackius, J. (2006). Strength and fatigue resistance of laser-mig hybrid butt-welds of an airframe aluminium alloy AA6013, Welding in the world, Vol.50, No.11/12, pages 88-97, ISSN 0043-2288

Vandewynckèle, A.; Vaamonde Couso, E. , Arias Otero, J. L. , Pérez de Lama, M., Rodríguez, G. Q., (2007). Laser-arc welding of duplex stainless steel, Laser Materials Processing Conference ICALEO2007 Congress Proceedings, pp.293-299, Orlando (FL), USA, Oct. 29-Nov. 1, 2007, LIA

Walz, C.; Stiebe-Springer, I., El Rayes, M., Seefeld, T., GerdSepold, (2001). Hybrid Welding of Steel for Offshore Applications, Proceedings of the Eleventh (2001) International Offshore and Polar Engineering Conference Stavanger, June 17-22, Norway, 2001.

Yan, J.; Zeng, X., Gao, M., Lai, J., Lin, T. (2009). Effect of welding wires on microstructure and mechanical properties of $2 \mathrm{~A} 12$ aluminum alloy in $\mathrm{CO}_{2}$ laser-MIG hybrid welding, Applied Surface Science, Vol.255, No.16, (May 2009), pp.7307-7313, ISSN 0169-4332

Yan, J.; Gao, M., Zeng, X. (2010). Study on microstructure and mechanical properties of 304 stainless steel joints by TIG, laser and laser-TIG hybrid welding, Optics and Lasers in Engineering, Vol.48, (Aug.2010), pp.512-517, ISSN 0143-8166 